\section{Bir Köpekte Eroziv Ülseratif Stomatitis: Çam Kesesi Böceği Toksikasyonu}

\section{Erosiv Ulcerative Stomatitis In A Dog: Pine Caterpillar Toxication}

Özet

Birçok kanatlı ve kelebek türünün yaşayan organizmalarda yangısal reaksiyon meydana getirdiği bilinmektedir. Çam kesesi böceği Lepidoptera familyasının bir üyesidir. Bu familya üyeleri çamlarda yaşamakta ve çam ağaçları, insanlar ve hayvanlara zarar verebilmektedir. Çam ağaçlarının iğne şeklindeki yaprakları ile beslenmesi bitkiler için yaşamı zorlaştırmakta, aynı zamanda bünyelerinde barındırdıkları allerjen özellikleri ile insan ve hayvanlarda sağlık problemlerine neden olmaktadır. Bu çalışmada bir av köpeğinde çam kesesi böceği temasına bağlı olarak gelişen eroziv stomatitis olgusu değerlendirildi.

Anahtar Kelimeler: Allerji, Köpek, Stomatit, Çam Kese Böceği

\begin{abstract}
In living organisms a lot of moths and butterflies are known to produce inflammatory reactions. The pine processionary is member of the Lepidopterans. This family's members lives in pine trees, and damage both the trees, humans, and animals. By feeding on the needles make hard to plants life and also cause health problems with their allergen structure in animals and humans. In the veterinary literature, there are some reports of exposure to PPM caterpillars in dogs, presented with urticarial reactions, angioedema, pruritus and tongue edema, vomiting, necrosis, salivation, lingual and sublingual edema, respiratory distress and the frequent sequel partial loss of the tongue. In this study, a case of erosive stomatitis was evaluated in a hunting dog that developed due to the contact of pine caterpillar.
\end{abstract}

Key Words: Pimobendan, Allergy, Dog, Stomatitis, Pine Caterpillar
Olgu Sunumu

Yasin Parlatır ${ }^{1}$

Hasan Erdoğan ${ }^{1}$

${ }^{1}$ Veteriner Fakültesi, İç Hastalıkları Anabilim Dalı Adnan Menderes Üniversitesi

\section{İletişim (Correspondence) \\ Hasan ERDOĞAN \\ hasan.erdogan@adu.edu.tr}

Makale Bilgisi Geliş: 06-03-2018 Kabul: 06-04-2018 


\section{Giriş}

İki yüzden fazla kanatlı ve kelebek türünün insanlarda yangısal reaksiyon meydana getirdiği bilinmektedir (Kawamoto ve Kumada, 1984). Çam kesesi böceği Lepidoptera familyasının bir üyesidir ve bu familya üyeleri çamlarda yaşamakta ve çam ağaçları, insanlar ve hayvanlara zarar verebilmektedir. $\mathrm{Bu}$ tür çam ağaçlarının iğne şeklindeki yaprakları ile beslendiği için bitkilerin yaşamını zorlaştırmakta, aynı zamanda bünyelerinde barındırdıkları allerjen özellikleri ile insan ve hayvanlarda sağlık problemlerine neden olmaktadır (Çetin vd., 2006).

Birçok tırtıl türü insan epidermisine penetre olarak mast hücrelerini etkileyen, kitinöz omurgaya sahip zehirli kıllar ile çevrilidir. Kitinöz omurga üzerinde bulunan bu zehirli kıllar toksik, irritan bir protein olan "thaumetopoein" salgılama özelliğine sahiptirler (Ducombs vd., 1979). Penetrasyon sonrasinda bu proteinler mast hücrelerini direkt etkileyerek IgE'den bağımsız bir degranülasyon meydana getirirler (Lamy vd., 1986). Bununla birlikte tırtıllar ile temas hikayesi olan insanlarda anafilaktik reaksiyonların oluştuğuna dair bilgiler de mevcuttur (Werno vd., 1993; Vega vd., 1997; Vega vd., 1999).

Kızarıklık, ödem, kaşıntı ve ağrı, tırtıllar ile temas sonrası meydana gelen en yaygın lokal kutaneöz reaksiyonlardır (Everson vd., 1990). Nadir olarak dispne, bronşitis, farengitis ve keratokonjuktivitis (Bishop ve Morton, 1967; Shama vd., 1982; Kawamoto ve Kumada, 1984) görülebilmekte, insanlarda gözlemlenebilen anafilaktik şok sendrom ve nöbet benzeri bulgular da köpeklerde tespit edilebilmektedir (Everson vd., 1990, Vega vd., 1997, Yıldar ve Güzel, 2013).

Veteriner literatür de köpeklerde Çam Kesesi Kelebeği (PPM) tırtılının etkisi hakkında fazla sayıda çalışma bulunmamakla birlikte sunulan çalışmalarda etken ile temas noktasında ürtiker reaksiyonları, anjiyo ödem, kaşıntı, dilde ödem, kusma, nekrozis, salivasyon, lingual ve sublingual ödem, respiratorik distres rapor edilmiştir (Bruchim vd., 2005; Niza vd., 2008; Yıldar ve Güzel, 2013). Nekrotik glossitisin takibinde kısmi dil kaybı en yaygın görülen sekel olarak bildirilmiştir (Grundman vd., 2000). Sunulan bu olguda çam kese böceği tırtılı ile temas eden bir av köpeğinin klinik değerlendirmesi yapılmıştır.

\section{Olgu Sunumu}

Adnan Menderes Üniversitesi Veteriner Fakültesi Acil Servis Kliniğine 5 yaşlı $15 \mathrm{~kg}$ ağırlı̆̆ındaki Pointer cinsi av köpeği 3 günlük iştah kaybı şikâyeti ve dışarıdan görülebilecek derecede ağız lezyonları ile getirildi. Hastanın kliniğe intikalinden 3 gün önce av dönüşü ödematöz ve hiperemik dil tablosu hasta sahibi tarafindan tespit edildiği ve veteriner hekime başvurularak antibiyotik ve nonstreoidal antienflamatuvar ilaçlar ile sağaltım denendiği ancak uygulama sonrasında herhangi bir iyileşmenin olmadığ 1 alınan anamnezde tespit edildi. $\mathrm{Bu}$ bilgilere ilaveten avlık alanda çam ağaçları üzerinde çam kese kurtlarının bulunduğu ve söz konusu hastanın avlanma esnasında bu tırtıllar ile temas ettiği belirlendi.

Hastanın fiziksel muayenesinde; pityalismus, lakrimasyon, kusma ve yüksek derecede salivasyon gözlemlendi. Ağız boşluğunda dil ve frenulum linguanın ödematöz karakterde olduğu, dilin ağız boşluğundan sarktığı görüldü. Dil ve diş etinde nekrotik ve ülseratif alanlar (Şekil 1) ve 3 günden beri süre gelen iştah kaybı sonucu letarji tespit edildi. 


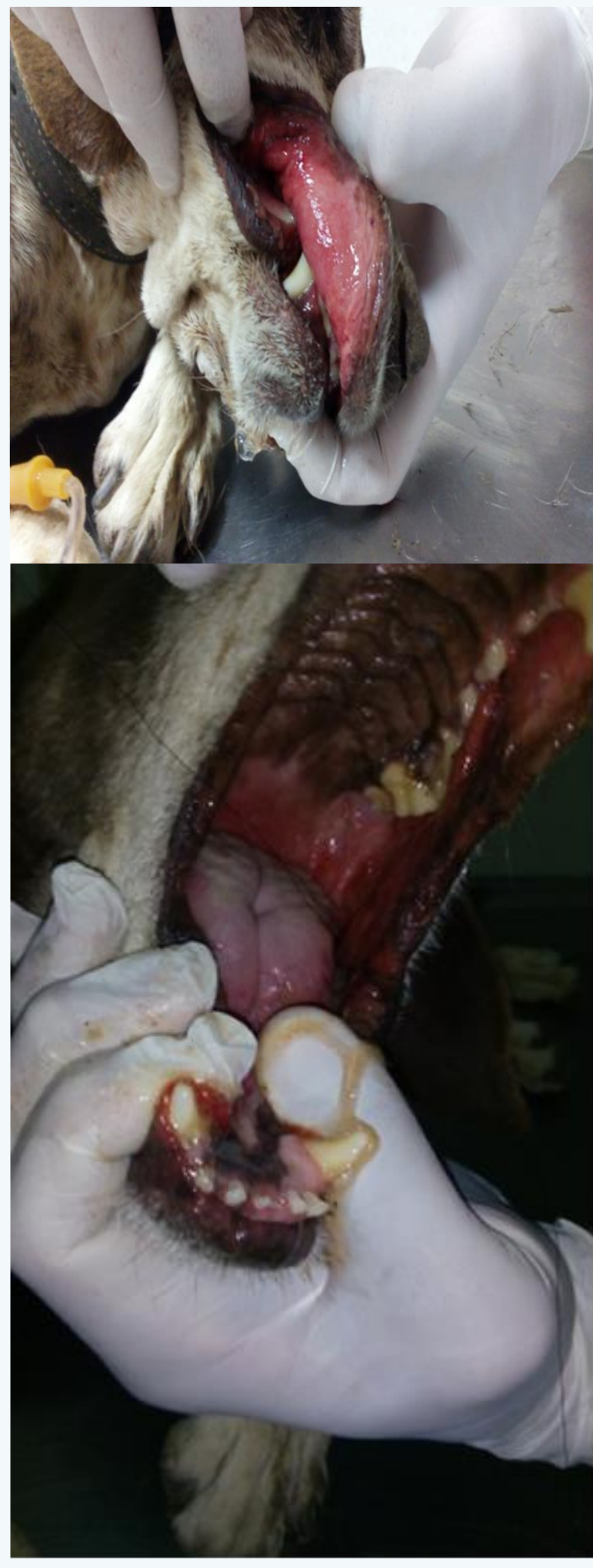

Şekil 1. Ağız boşluğunda nekrotik, ülseratif alanlar ve dil ve gingivida tespit edilen nekrotik, ülseratif alanlar. Figure 1. Necrotic, ulcerative areas in oral cavite, necrotic, ulcerative areas on tongue and gingiva
Yapılan hematolojik değerlendirmelerde WBC, NEU, RBC ve HCT konsantrasyonlarının fizyolojik sınırlar içerisinde olduğu belirlendi. Sağaltım öncesinde ve sonrasında yapılan hematolojik değerlendirmede herhangi bir anlamlı değişimin olmadığı tespit edildi.

Hastanın ağız boşluğunun \% $0.9 \mathrm{NaCl}$ solüsyonu ile yıkama işlemi gerçekleştirildikten sonra rehidrasyonun sağlanması için \% $0.9 \mathrm{NaCl}(500 \mathrm{ml}), \% 5$ Dekstroz (500 ml) ve İzolen (500 ml) preparatları intravenöz (IV) olarak, toplamda $60 \mathrm{ml} / \mathrm{kg} /$ gün olacak şekilde uygulandı. Beş gün süre ile antihistaminik, Mepiramin maleat ve klarbutanol, $1 \mathrm{mg} / \mathrm{kg}$, IV) (Histavet, Vetaş, Türkiye) ve kortikosteroid (methylprednisolone, $3 \mathrm{mg} / \mathrm{kg}$, IV), Prednol-L 40 mg (Mustafa Nevzat, Türkiye) uygulaması yapıldı. Nekrotik alanların rejenerasyonunu sağlamak amacı ile Vitamin $\mathrm{C}$ (Redoxon ampul, Bayer, Türkiye) ve dexpanthenol (11mg/kg, IV, Bepanthene ampul, Bayer, Türkiye) uyguland1. Aynı zamanda Vitamin B kompleks (Nervit $3 \mathrm{mg} / \mathrm{kg}$ subkutan (SK), VETAŞ, Türkiye), ve lokal ağrının giderilmesi için lidokain (Dentinox jel, Abdi İbrahim, Türkiye) uygulamaları gerçekleştirildi. Sağaltım uygulamalarına toplam beş gün süre ile devam edildi ve klinik iyileşme (Şekil 2) sağlandı.

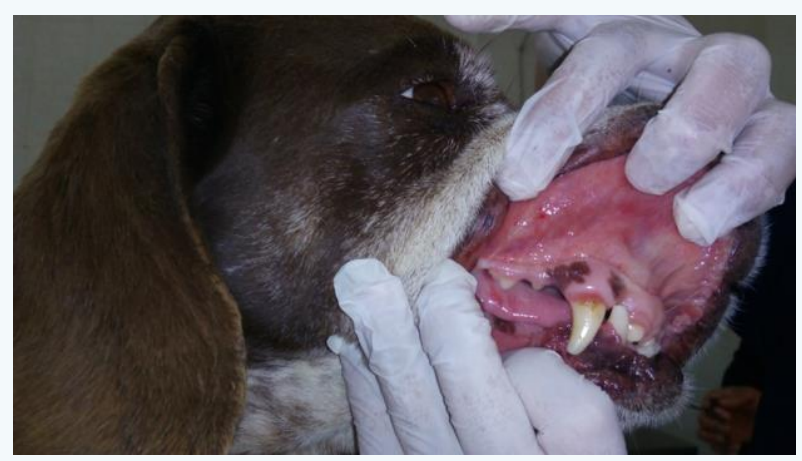

Şekil 2. Tedavi sonrası mukozal ve gingival görüntü Figure 2. Mucosal and gingival view after treatment 


\section{Tartışma ve Sonuç}

Çam keseleri hayatları boyunca tam bir değişim göstermektedirler (Holometabolous). Yaşam siklusu yumurta, larva), pupa ve yetişkin olmak üzere 4 evreden oluşmaktadır (İpekdal, 2005). Yumurta evresi yetişkin kelebeklerin çam ağacı iğne yapraklarına yumurtalarını dökmesi ile başlar. Yumurtadan çıktıktan sonra etrafı daha sonradan ipek iplik özelliği kazanan ağızdan salgılanan salgı ile sarılır. Kış aylarına bu koruyucu kalkan eşliğinde girerler (Hódar vd., 2003). Bölgesel iklim şartlarına göre değişmek kaydıyla genellikle şubat sonu ve mayıs başlangıcında gelişimlerini tamamlarlar. Çoğunlukla sabahın erken saatlerinde yere düşer ve pupa evresinde girerler. $\mathrm{Bu}$ kitlesel hareket sürü psikolojisi olarak adlandırılır. Larvaların göstermiş olduğu kitlesel hareketlenme çam kesesi böceğinin çam kesesi kelebeği olarak adlandırılmasına öncü olmuştur (İpekdal, 2005). Bir Akdeniz ve Avrupa ülkesi olan Türkiye'de, çam kesesi kelebeği tırtılının yaşadığı normal hayat döngüsü çerçevesinde tırtılın yere düşüşü sıklıkla gözlemlenmektedir. Genellikle bu etken ile etkileşim Şubat ve Mayıs aylarında mevsimsel geçişin gerçekleştiği zamanda meydana gelmektedir. Özellikle L4 ve L5 evrelerinde etkeni saran k1llar toksik özellikteki proteini ihtiva ederler (Bruchim vd., 2005; Diaz, 2005; İnal ve Altıntaş, 2006). Pupa periyodunda larva L5 evresi yaşanılan bölgenin iklim şartlarına göre değişmek üzere Şubat ve Mayıs aylarında yere ulaşırlar. $\mathrm{Bu}$ olguda hastanın etken ile teması Mayıs ayı sonlarında gerçekleşmiş ve olgunun gerçekleştiği zaman etkenin hayat döngüsü ile uyum göstermiştir. Kliniğimize teşhis ve sağaltım amacı ile getirilen olgunun anamnezinde vakanın riskli tarih aralığ içerisinde olduğu ve çam kese böceklerinin avlık alan içerisinde bulunduğu belirlendi. Özellikle kıyı ege şeridi içerisinde çamlık alanlarda yapılan avcılık sporu girişimlerinde köpeklerin söz konusu temas ile korunması gerektiği ve avcıların konu ile ilişkili olarak bilgilendirilmesinin gerekli olduğu düşünüldü.

Çam kese böceğinin L4 ve L5 evrelerinde böceği saran k1llar toksik özellikteki protein ihtiva ettiğinden bu dönemde temas edilen yola göre canlıda çeşitli reaksiyonlar gözlemlenebilmektedir (Diaz, 2005; Bruchim vd., 2005; İnal ve Altıntaş, 2006). Etkenin yapısında bulunan toksik özellikteki bu proteinler temas edilen bölgede nekrotik, ülseratif ve ödematöz reaksiyonlar meydana getirmektedirler. Elde edilen veriler 1şığında çoğunlukla ağız yolu ile temas gerçekleşmektedir. Etken ağız boşluğunda dil, damak ve diş etlerinde nekroza, ülserasyona ve ödematöz oluşumlara yol açar. Dil kısmi olarak kaybedilebilir. Ayrıca sindirim sisteminde meydana getirdiği reaksiyonlar sonucu abdominal ağrı, kusma ve mide bağırsak kanalında yangısal reaksiyonlara neden olmaktadır. Sindirim sisteminin geniş bir kısmında meydana gelen bu oluşumlar sonucunda aşırı salivasyon, egzersiz intolerans, iştah kaybı ve genel durum düşüklüğünün görülmesi kaçınılmazdır. Olgumuzda değerlendirilen köpekte şekillenen temasın literatürlerde gösterildiği şekilde ağız yolu ile gerçekleştiği ayrıca olguda tespit edilen pityalismus, iştah kaybı, depresif tablo, abdominal ağrı ve iştahsızlık verilen bilgiler ile paralellik göstermektedir. Bununla beraber başvurulan kaynaklar ile uyumlu bir şekilde nekrotik, ülseratif ve ödematöz tablo olgumuzu oluşturan köpeğin ağzında da gözlemlenmiştir.

Hastanın muayenesi gerçekleştirildikten ve anamnez bilgileri alındıktan sonra hastanın prognozunun belirlenebilmesi amacı ile sağaltım 5 gün süre ile takip edildi ve parenteral sağaltım uygulamalarından sonra yapılan kontrolde hastanın oral lezyonlarının kaybolduğu ve tamamen iyileştiği belirlendi. 
Sunulan bu olguda ülkemizde yaygın olarak bulunan Çam Kesesi Kelebeği larvasının temasına bağlı olarak gelişen stomatitis tablosu ve rutin sağaltım denemeleri değerlendirilmiştir. Söz konusu etiyolojik ajan ülkemizde yaygın bir şekilde bulunmaktadır. Avcılık, dağcılık, doğa yürüyüşü gibi doğa sporları ile ilgilenen insanlar ve hayvanlar açısından konu değerlendirildiğinde risk grubu içerisinde bulunan insan ve hayvanların sağlığ açısından önem arz etmektedir. Bir köpekte rutin sağaltım uygulamalarının değerlendirildiği bu olguda, ülkemizde yaygın görülen bu tırtılın hayvanlar ve insanlarda oluşturabileceği lezyonlar ve riskleri nedeniyle sportif avcılar ve doğa severler özelinde anlamlı ve önemli bir farkındalık oluşturacağı kanaatine varıld.

\section{Kaynaklar}

Bishop JW, Morton MR, (1967): Caterpillar-hair keratoconjunctivitis. Am J Ophthalmol, 64(4), 778-779.

Bruchim Y, Ranen E, Saragusty J, Aroch I, (2005): Severe tongue necrosis associated with pine processionary moth (Thaumetopoea wilkinsoni) ingestion in three dogs. Toxicon 45, 443-447.

Çetin H, Erler F, Yanikoglu A, (2006): Toxicity of essential oils extracted from Origanum onites L. and Citrus aurentium L. against the pine processionary moth, Thaumetopoea wilkinsoni Tams Folia Biol. (Krakow), 153157.

Diaz JH. (2005): The evolving global epidemiology, syndromic classification, management, and prevention of caterpillar envenoming. Am J Trop Med Hyg. 2005; 72(3), 347-357.

Ducombs G, Lamy M, Bergaud JJ, Tamisier JM, Gervais C, Texier L, (1979): La chenille processionnaire (Thaumetopea pityocampa Schiff Lepidopteres) et l'homme: etude morphologique de l'appareil urticant Enquete epidemiologique. Annalesde Dermatologie et de Venerologie, 105 (10), 769-778.
Everson GW, Chapin JB, Normann SA, (1990): Caterpillar envenomations: a prospective study of 112 cases. Vet Hum Toxicol, 32 (2), 114-119.

Grundmann S, Arnold P, Montavon P, Schraner EM, Wermelinger B, Hauser B, (2000): Toxic tongue necrosis from processional pine caterpillar (Thaumetopoea pityocampa Schiff.). Kelintierpraxis, 45(1), 45-50.

Hódar JA, Castro J, Zamora R. (2003): Pine processionary caterpillar Thaumetopoea pityocampa as a new threat for relict Mediterranean Scots pine forests under climatic warming. Biol Conserv, 110, 123-129.

İnal A, Altintaş DU. (2006): Güvenmez HK, Yilmaz M, Kendirli SG. Life-threatening facial edema due to pine caterpillar mimicking an allergic event. Allergol Immunopathol, 34(4), 171-173.

İpekdal K. (2005): Studies on bio-ecology and control of pine processionary moth Thaumetopoea pityocampa (Denis \& Schiffermüller, 1775) (Lepidoptera: thaumetopoeidae). Hacettepe Üniversitesi, Fen Bilimleri Enstitüsü, Yüksek Lisans Tezi, (in Turkish with an abstract in English).

Kawamoto F, Kumada N. (1984): Biology and venoms of Lepidoptera, In: Tu AT editor, Insects Poison, Allergens and Other Invertebrate Venoms. Chapter 9, Marcel Dekker, New York.

Lamy M, Pastureaud MH, Novak F, Ducombs G, Vincendean $P$, Malerille $J$, Texier L, (1986). Thaunetopoein: an urticating protein from the hairs and integument of the pine processionary caterpillar (Thaumatopoea pityocampa Schiff). Toxicon, 24, 347-356.

Niza ME, Ferreira RL, Coimbra HM, Guerreiro NM, Felix JM, Matos TV, Vilela CL, (2008). Effects of Pine Processionary Caterpillar Thaumetopoea pityocampa Contact in Dogs: 41 Cases (2002-2006). Zoonoses and Public Health.

Shama SK, Etkind PH, Odell TM, Canada AT, Finn AM, Soter NA, (1982). Gypsy moth caterpillar dermatitis. N Engl J Med, 306(21): 1300-1301.

Vega JM, Moneo I, Armentia A, Fernandez A, Vega J, De LaFuente R, Sanchez P, Sanchis ME, (1999). Allergy to the pine processionary caterpillar (Thaumetopoea pityocampa). Clinical and Experimental Allergy, 29, 14181423. 
Vega JM, Moneo I, Armentia A, Lopez-rico R, Curiel G,

Bartolome B, Fernandez A, (1997). Anaphylaxis to a pine caterpillar. Allergy, 52, 1244-1245.

Werno J, Lamy M, Vincendeau P, (1993). Caterpillars hairs as allergens. Lancet, 342, 936-937.

Yıldar E, Güzel Ö, (2013). Tongue necrosis in a dog associated with the pine processionary caterpillar and its treatment. Turk J Vet Anım Sci, 37, 238-241. 